\title{
Root growth in response to nitrogen supply in Chinese maize hy- brids released between 1973 and 2009
}

\author{
WU QiuPing, CHEN FanJun, CHEN YanLing, YUAN LiXing, \\ ZHANG FuSuo \& MI GuoHua* \\ Key Laboratory of Plant-Soil Interaction, MOE, College of Resources and Environmental Science, \\ China Agricultural University, Beijing 100193, China
}

\begin{abstract}
Root growth has a fundamental role in nitrogen $(\mathrm{N})$ use efficiency. Nevertheless, little is known about how modern breeding progress has affected root growth and its responses to $\mathrm{N}$ supply. The root and shoot growth of a core set of 11 representative Chinese maize (Zea mays L.) hybrids released between 1973 and 2009 were investigated under high $\mathrm{N}\left(4 \mathrm{mmol} \mathrm{L} \mathrm{L}^{-1}, \mathrm{HN}\right)$ and low $\mathrm{N}\left(0.04 \mathrm{mmol} \mathrm{L} \mathrm{L}^{-1}, \mathrm{LN}\right)$ levels in a solution culture system. Compared with LN, HN treatment decreased root dry weight (RDW), the root: shoot ratio $(R / S)$, and the relative growth rate for root dry weight $\left(\mathrm{RGR}_{\text {root }}\right)$, but increased the total root length (TRL) and the total lateral root length (LRL). The total axial root length (ARL) per plant was reduced under HN, mostly in hybrids released before the 1990s. The number of seminal roots (SRN) was largely unaffected by different N levels. More recently released hybrids showed higher relative growth rates in the shoot under both HN and LN. However, the roots only showed increased RGR under HN treatment. Correspondingly, there was a positive linear relationship with the year of hybrid release for TRL, LRL and ARL under HN treatment. Together, these results suggest that while shoot growth of maize has improved, its root growth has only improved under high $\mathrm{N}$ conditions over the last 36 years of selective breeding in China. Improving root growth under $\mathrm{LN}$ conditions may be necessary to increase the $\mathrm{N}$ use efficiency of maize.
\end{abstract}

Root, $R / S$ ratio, nitrogen, relative growth rate, maize breeding

Citation: Wu Q P, Chen F J, Chen Y L, et al. Root growth in response to nitrogen supply in Chinese maize hybrids released between 1973 and 2009 . Sci China Life Sci, 2011, 54: 642-650, doi: 10.1007/s11427-011-4186-6

Genetic improvement has played a significant role in increasing maize grain yield over the last 50 years [1-6]. The average maize grain yield has increased linearly by about $100 \mathrm{~kg}$ (ha year) $^{-1}$ in the USA between 1939 and 2004 [2,7]. In China, the average genetic yield gain was $84-124 \mathrm{~kg}$ (ha year) ${ }^{-1}$ for maize grown in North China since 1970 [5,8]. In maize breeding programs, plants are routinely grown with high levels of nitrogen $(\mathrm{N})$ fertilizer because $\mathrm{N}$ is one of the most important nutrients limiting plant growth. However, the intensive use of $\mathrm{N}$ fertilizers in agriculture has and will continue to have major detrimental impacts on the environment

*Corresponding author (email: miguohua@cau.edu.cn) because of the inefficient use of $\mathrm{N}$ by crops, which typically use approximately one-third of total $\mathrm{N}$ applied [9].

Roots play a vital role in anchoring the plant and in water and nutrient uptake from the soil. Therefore, they directly affect yield [10]. Genotypic differences in root morphology at the seedling growth stage can markedly influence nitrate acquisition [11,12]. Genetic control of maize root traits has been shown in many studies [13]. Interestingly, some of the QTLs associated with root length density, root diameter, secondary lateral root number, and vertical root pulling resistance were closely linked with QTLs for leaf greenness and for nitrogen uptake [14-16]. For various reasons, however, the genetic variations in root traits have been ne- 
glected in modern breeding processes. Increasing crop yields through applying more fertilizer and water has reached a maximum [17]. To achieve high yielding and eco-friendly agriculture, there is significant interest in improving the capacity of plants to uptake and use nutrients, and the focus should be on improving the function of the root system $[17,18]$.

Although some authors hypothesized that root systems of cereals could have suffered from intense selection pressure for increased above-ground biomass or grain yield [19], little is known about effects of breeding pressure on the ability of the root system to adapt to variations in environmental conditions, for example to variations in $\mathrm{N}$ availability [20]. In wheat, modern dwarf varieties show reduced investment in root dry matter and root length density, and thus, have a lower root to shoot ratio early in the growing season [19]. In maize, the importance of a good root system has been recognized since the beginning of modern breeding [21]. Despite the significant genetic variations in root characteristics and architecture in maize [22,23], there has been little progress made in using root traits as selection criteria to indirectly improve yield [24]. This is because of the complexity of root systems and the difficulties of investigating roots of a large number of plants, especially in field studies. Using a modeling approach, Hammer [25] provided evidence for the concept that, in comparison to shoot architecture, a change in root system architecture has the greater effect on increasing maize yield when water is available at sowing.

Evaluating root growth in the field is compounded by the high heterogeneity of soil conditions and environmentx genotype interactions [26]. Root development at the seedling stage is very important for plant establishment and is closely related to grain yield [27]. In addition, root characteristics at an earlier ontogeny show higher heritability than those at later stages [28]. Feil [29] suggested that seedling root traits might be used as early selection criteria for water use efficiency in breeding studies. In this study, we aimed to evaluate whether the high $\mathrm{N}$ inputs used in modern maize breeding programs affect root growth, and hence, $\mathrm{N}$ use efficiency. We selected 11 representative maize hybrids released from 1973 to 2009 in China to investigate root growth traits and root responses to variations in $\mathrm{N}$ availability using a solution culture system.

\section{Materials and methods}

\subsection{Plant materials}

Table 1 shows the 11 maize (Zea mays L.) hybrids released from 1973 to 2009 that were used in this study. These hybrids were the dominant hybrids used in Chinese agriculture at the time of their release. The planting area for each of the hybrids exceeded 5000000 ha in China between 1980 and 2009 [30,31]. Except for Xianyu 335, which was bred by the Pioneer Company Ltd., all the other hybrids were developed by Chinese breeders.

\subsection{Plant culture}

Seeds were sterilized in $10 \%$ (v/v) $\mathrm{H}_{2} \mathrm{O}_{2}$ for $30 \mathrm{~min}$, washed with distilled water, and then soaked in saturated $\mathrm{CaSO}_{4}$ solution with continuous aeration supplied by an electric pump for approx. $12 \mathrm{~h}$. Then, seeds were placed between sheets of filter paper soaked with $\mathrm{CaSO}_{4}$ solution and germinated in the dark at room temperature. When the roots were approx. $1 \mathrm{~cm}$ long, uniform seedlings were wrapped in filter paper and carefully transferred into a plastic container filled with distilled water for continued growth. As soon as two leaves were visible the seedlings were transferred into porcelain pots containing $2 \mathrm{~L}$ nutrient solution. Their endosperms were removed at this time. These plants were grown in a growth chamber under the following conditions: $28 / 22^{\circ} \mathrm{C}$, $14 / 10 \mathrm{~h}$ light/dark cycle. During the light cycle, the photosynthetic photon flux density was $250-300 \mu \mathrm{mol} \mathrm{m}{ }^{-2} \mathrm{~s}^{-1}$ at canopy height. Plants were grown in a nutrient solution with the following constituents $\left(\mathrm{mmol} \mathrm{L}^{-1}\right): 0.75 \mathrm{~K}_{2} \mathrm{SO}_{4}, 0.1$

Table 1 Characteristics of hybrids used in this experiment

\begin{tabular}{|c|c|c|c|}
\hline Hybrids & Parents & Breeders & Year of release \\
\hline Zhongdan 2 & Mo17×Zi330 & Chinese Academy of Agricultural Sciences & 1973 \\
\hline Huang 417 & Huangzao4×Mo17 & Beijing Academy of Agricultural and Forestry Sciences & 1978 \\
\hline Danyu 13 & Mo17×E28 & Academy of Agricultural Sciences in Dandong, Liaoning Province & 1979 \\
\hline Shendan7 & $5003 \times \mathrm{E} 28$ & Academy of Agricultural Sciences in Shenyang, Liaoning Province & 1982 \\
\hline Nongda 60 & $5003 \times$ Zong 31 & Chinese Agricultural University & 1985 \\
\hline Yedan 13 & Ye478×Dan 340 & Academy of Agricultural Sciences in Laizhou, Shandong Province & 1989 \\
\hline Zhengdan 958 & Zheng58×Chang7-2 & Academy of Agricultural Sciences in Henan Province & 1996 \\
\hline Jundan 20 & $9058 \times$ Jun $92-8$ & Academy of Agricultural Sciences in Henan Province & 1998 \\
\hline Xianyu 335 & PH6WC $\times$ PH4CV & Pioneer Co., Ltd. & 2000 \\
\hline Denghai 661 & DH351×DH372 & Shandong Denghai Seeds Co., Ltd. & 2009 \\
\hline
\end{tabular}


$\mathrm{KCl}, 0.25 \mathrm{KH}_{2} \mathrm{PO}_{4}, 0.65 \mathrm{MgSO}_{4}$, and 0.13 EDTA-Fe, and (in $\mu \mathrm{mol} \mathrm{L} \mathrm{L}^{-1}$ ): $1.0 \mathrm{MnSO}_{4}, 1.0 \mathrm{ZnSO} 4,0.1 \mathrm{CuSO} 4$, and $0.005\left(\mathrm{NH}_{4}\right)_{6} \mathrm{Mo}_{7} \mathrm{O}_{24}$. We used a completely randomized design, with four replicate pots (5 plants/pot) for each treatment. Plants were supplied with one-half strength complete nutrient solution containing $4.0 \mathrm{mmol} \mathrm{L}^{-1} \mathrm{NO}_{3}^{-}$for $1 \mathrm{~d}$ and then supplied with complete nutrient solution for another $4 \mathrm{~d}$. Two plants from each pot were sampled at this stage, and the remaining three plants were supplied with either 0.04 (low $\mathrm{N}, \mathrm{LN}$ ) or $4.0 \mathrm{mmol} \mathrm{L}^{-1} \mathrm{NO}_{3}^{-}$(high $\mathrm{N}, \mathrm{HN}$ ), respectively, for another $6 \mathrm{~d}$. The nitrate concentration of $4 \mathrm{mmol} \mathrm{L}^{-1}$ is approximately equal to the mean nitrate level in soil solution [32]. As determined in our previous work [12], an $\mathrm{NO}_{3}^{-}$supply at $4 \mathrm{mmol} \mathrm{L}^{-1}$ is optimal for maximizing root growth. Nitrate was added to the substrate in the form of $\mathrm{Ca}\left(\mathrm{NO}_{3}\right)_{2}$. In the low $\mathrm{NO}_{3}^{-}$treatments, $\mathrm{Ca}_{2}^{+}$ was complemented by adding $\mathrm{CaCl}_{2}$ to the same level as in the $4.0 \mathrm{mmol} \mathrm{L}^{-1} \mathrm{NO}_{3}^{-}$treatments. For all growth solutions, the $\mathrm{pH}$ was adjusted to $6.0 \pm 0.1$ with $\mathrm{KOH}$. The nutrient solution was renewed every other day and was aerated continuously by an electric pump.

\subsection{Sampling and measurements}

Plants were sampled on the first day of $\mathrm{N}$ treatments and again on the sixth day. Shoots and roots were separated by cutting at the mesocotyl. At the second harvest, the lower two leaves of LN plants were yellow, a typical symptom of $\mathrm{N}$-deficiency. Leaf length and width were measured with a ruler and leaf area was calculated by the following formula: leaf length $\times$ maximum width $\times k$, where $k$ is a shape factor with a value of 0.5 for partially unfolded leaves and 0.75 for completely unfolded leaves [33]. Shoots were then dried at $70^{\circ} \mathrm{C}$ to constant weight and weighed. The relative growth rate (RGR) was determined as described by Botella et al. [34], as follows:

$$
\mathrm{RGR}=\left(\ln W_{2}-\ln W_{1}\right) /\left(t_{2}-t_{1}\right),
$$

where $W_{1}$ and $W_{2}$ are the dry biomass at the first $\left(t_{1}\right)$ and second $\left(t_{2}\right)$ samplings and $\ln$ is the natural logarithm. The RGR for shoot dry weight $\left(\mathrm{RGR}_{\text {shoot }}\right)$ was then calculated.

We counted the number of axial roots, including seminal roots and crown roots, and measured root length with a ruler. The roots were then scanned (Epson V700, Beijing, China). During scanning, the root was placed in a glass dish containing water to untangle the roots and to minimize root overlap. Images were analyzed for total root length per plant (TRL) using WinRHIZO (Vision Pro 5.0a, Canada). The total length of the lateral root (LRL) was calculated from the difference between TRL and ARL. The roots were then dried and weighed to calculate the RGR for root dry weight $\left(\mathrm{RGR}_{\text {root }}\right)$ according to formula (1). The root to shoot ratio $(R / S)$ was calculated by the ratio of root dry weight to shoot dry weight at the final harvest. The ratio of LN/HN for both
SDW and RDW was calculated, and these values were used as indicators of responses to low $\mathrm{N}$ supply.

\subsection{Statistical analysis}

The experimental data were analyzed by analysis of variance using the SAS statistics system (SAS, 1994). Differences were compared using LSD at the $P \leqslant 0.05$ probability level. Shoot and root parameters were plotted against the year of hybrid release, and regression analysis was conducted using simple linear models $(Y=a+b X)$. For the regression analysis, a few irregular data that deviated significantly from the linear relationship were omitted (as indicated in figures).

\section{Results}

\subsection{Effect of nitrogen×genotype (hybrid) interaction on shoot and root growth}

The effect of $\mathrm{N}$ treatment was significant for all the root and shoot parameters tested except for the number of seminal roots (SRN) and total axial roots number (ARN) (Table 2). Compared with LN, HN increased shoot dry weight (SDW), relative shoot growth rate $\left(\mathrm{RGR}_{\text {shoot }}\right)$, leaf area (LA), total root length (TRL), and total length of lateral roots (LRL), but reduced root dry weight (RDW), relative root growth rate $\left(\mathrm{RGR}_{\mathrm{root}}\right)$, root to shoot ratio $(R / S)$ and total length of axial roots (ARL) (Figure 1). The genotype had a significant influence on all the root and shoot growth attributes, suggesting that both shoot and root traits have greatly changed over the past decades. The Nxgenotype interactions were

Table 2 Variance analysis of effects of N, genotype (hybrid), and $\mathrm{N} \times$ genotype interaction on shoot and root growth parameters of maize ${ }^{\text {a) }}$

\begin{tabular}{cccc}
\hline Source of variation & $\mathrm{N}$ & $\begin{array}{c}\text { Genotype } \\
\text { (hybrid) }\end{array}$ & N×genotype \\
\hline Shoot biomass & $* * *$ & $* * *$ & $\mathrm{NS}$ \\
Root dry weight & $* * *$ & $* * *$ & $* * *$ \\
Root/shoot ratio & $* * *$ & $* * *$ & $\mathrm{NS}$ \\
Relative growth rate for shoot bio- & $* * *$ & $* * *$ & $\mathrm{NS}$ \\
mass & & & $* *$ \\
Relative growth rate for root dry & $* * *$ & $* * *$ & $* * *$ \\
Leaf area & $* * *$ & $* * *$ & $* * *$ \\
Total root length & $* * *$ & $* * *$ & $* * *$ \\
Total lateral root length & $* * *$ & $* * *$ & $* * *$ \\
Total axial root length & $* * *$ & $* * *$ & $* * *$ \\
Total axial root number & $\mathrm{NS}$ & $* * *$ & $\mathrm{NS}$ \\
Seminal root number & $\mathrm{NS}$ & $* * *$ & $\mathrm{NS}$ \\
\hline
\end{tabular}

a) We used 11 hybrids released in different areas in China. Plants were precultured in complete nutrient solution containing $4.0 \mathrm{mmol} \mathrm{L}^{-1} \mathrm{NO}_{3}^{-}$for $5 \mathrm{~d}$ before being treated with two different $\mathrm{NO}_{3}^{-}$levels, high $\mathrm{N}\left(4 \mathrm{mmol} \mathrm{L}^{-1}\right)$ and low $\mathrm{N}\left(0.04 \mathrm{mmol} \mathrm{L}^{-1}\right)$ for another $6 \mathrm{~d}$ and then harvested. $* *$ and $* * *$ denote significant at the 0.01 and 0.001 probability level, respectively. NS, Not significant. 


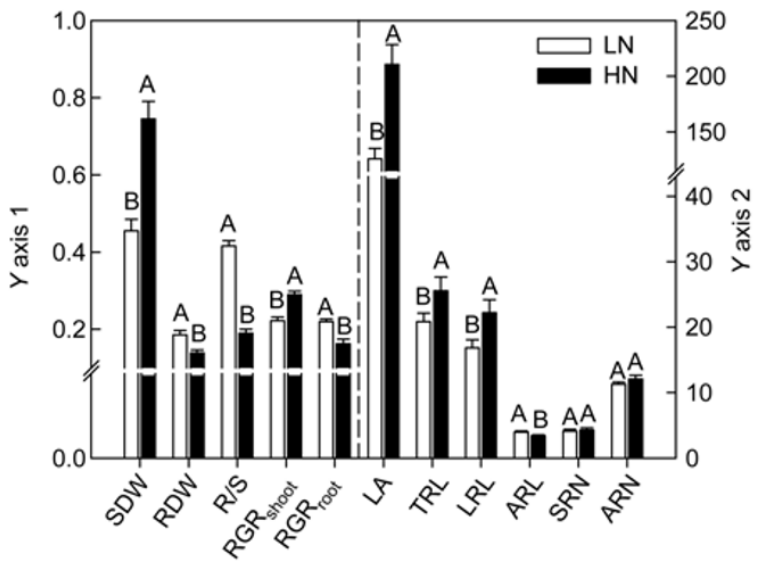

Figure 1 Effect of $\mathrm{N}$ supply on shoot and root growth traits. SDW (g plant $^{-1}$ ), shoot dry matter; RDW (g plant ${ }^{-1}$ ), root dry weight; $R / S$, root to

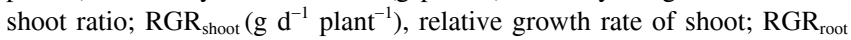
$\left(\mathrm{g} \mathrm{d}^{-1}\right.$ plant $\left.{ }^{-1}\right)$, relative growth rate of root; LA $\left(\mathrm{cm}^{2}\right.$ plant $\left.{ }^{-1}\right)$, leaf area per plant; TRL $\left(\mathrm{m}\right.$ plant $\left.^{-1}\right)$, total root length; LRL $\left(\mathrm{m} \mathrm{plant}^{-1}\right)$, total lateral length; ARL (m plant ${ }^{-1}$ ), total axial root length; SRN (number plant ${ }^{-1}$ ), seminal root number; ARN (number plant ${ }^{-1}$ ), axial root number. SDW, $\mathrm{RDW}, \mathrm{R} / \mathrm{S}, \mathrm{RGR}_{\text {shoot}}$, and $\mathrm{RGR}_{\text {root }}$ were plotted against $Y$ axis 1; LA, TRL, ARL, SRN, ARN were plotted against $Y$ axis 2.

not significant for the following parameters: $\mathrm{RGR}_{\text {shoot }}$, SDW, $R / S$ ratio, SRN and ARN (Table 2, Figure 1), suggesting that the response of the hybrids to $\mathrm{N}$ was similar for these parameters. However, there were significant $\mathrm{N} \times$ genotype interactions for other traits, especially root traits. These findings imply that the response of root growth and root morphology to $\mathrm{N}$ levels differs among hybrids released in different eras.

\subsection{Change in shoot and root parameters vs. year of hybrid release}

\subsubsection{Shoot and root dry weight}

The total shoot dry weight (SDW) of the 11-day-old maize seedlings was lower in more recently released cultivars in both LN $(r=-0.54, P<0.10)$ and $\mathrm{HN}(r=-0.58, P<0.10)$ treatments (Figure 2), except for the hybrid Denghai 661, which showed a higher value for SDW. Therefore, the response of SDW to low N stress, as indicated by the LN/HN ratio, was similar among hybrids (Figure 2A; Table 2). With increasing year of hybrid release, root dry weight (RDW) was unchanged in $\mathrm{HN}$, but decreased in LN ( $r=-0.65$, $P<0.05$ ) (Figure 2B). That is, the roots of the new hybrids were less responsive to $\mathrm{LN}$, as indicated by the decreasing $\mathrm{LN} / \mathrm{HN}$ ratio $(r=-0.63, P<0.05)$.
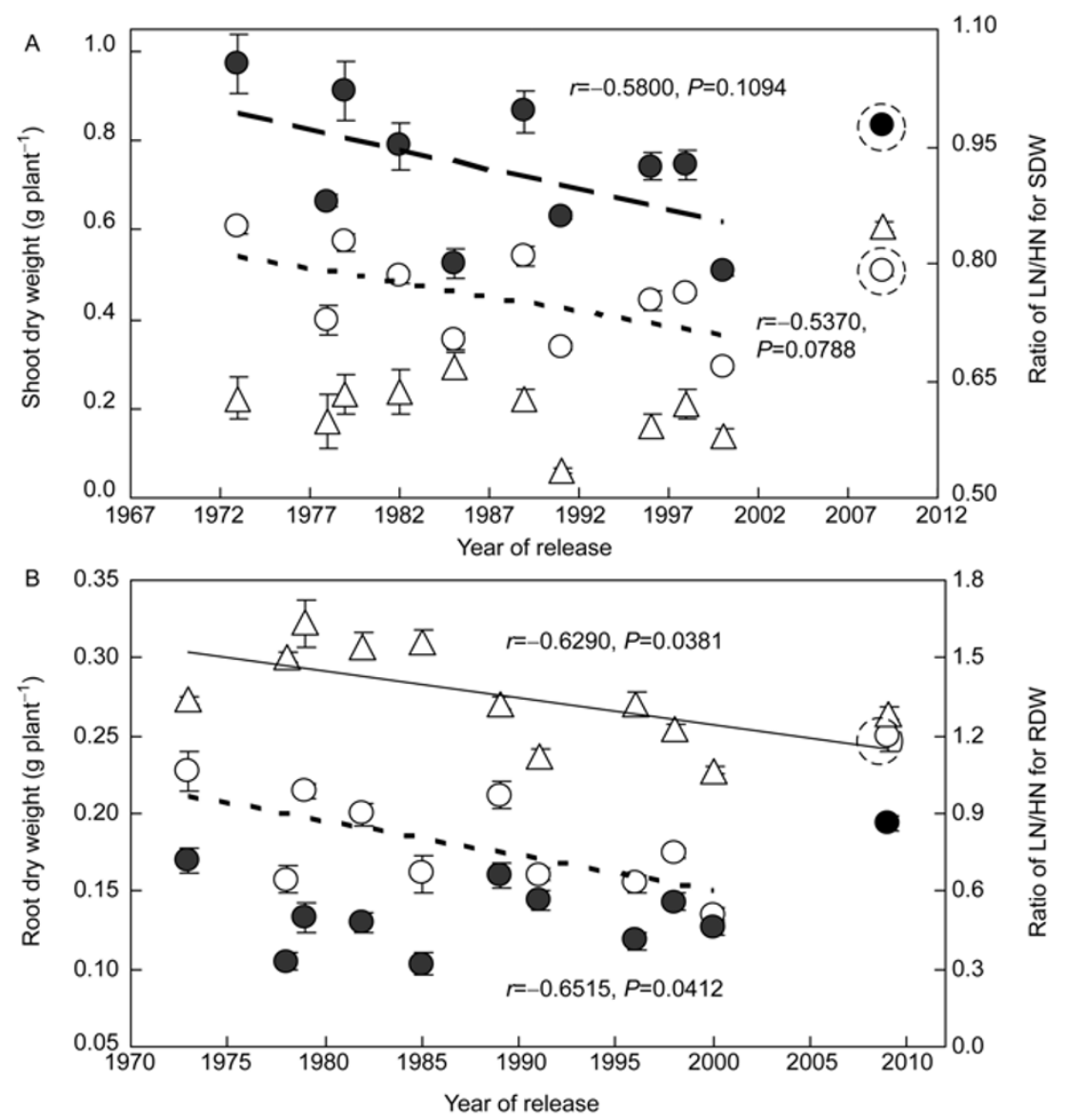

Figure 2 Shoot dry weight (SDW, upper panel) and root dry weight (RDW, lower panel) of maize seedlings plotted against year of hybrid release. Data represent the average of four replicates. Open circles denote low $\mathrm{N}$ treatment, solid circles denote high $\mathrm{N}$ treatments, triangles denote ratio of low $\mathrm{N}$ to high $\mathrm{N}$ treatment for either SDW or RDW. Dashed line, dotted line, and solid line are linear regressions for HN, LN and LN/HN, respectively. Data point omitted from regression analysis is circled. 


\subsubsection{Root to shoot ratio $(R / S)$}

The root to shoot ratio $(R / S)$ ranged from 0.38 to 0.49 under $\mathrm{LN}$, and from 0.15 to 0.25 under HN. Regardless of $\mathrm{N}$ treatments, the root to shoot ratio $(R / S)$ increased with increasing year of hybrid release (Figure 3; Table 2). Thus, the allocation of biomass to roots is greater in newly released hybrids. The only exception was hybrid ZD958, which showed the lowest $R / S$ under low $\mathrm{N}$.

\subsubsection{Relative growth rate of shoot and root}

In both $\mathrm{N}$ treatments, the relative growth rate for shoot dry weight $\left(\mathrm{RGR}_{\text {shoot }}\right)$ of maize seedlings increased with increasing year of hybrid release ( $r=0.70$ and 0.65 for $\mathrm{LN}$ and HN, $P<0.05$, respectively) (Figure 4A). However, the RGR for root dry weight $\left(\mathrm{RGR}_{\text {root }}\right)$ was only positively correlated with the year of hybrid release under $\mathrm{HN}(r=0.71, P<0.05)$ (Figure 4B), except for hybrid ZD958, which had the least $\mathrm{RGR}_{\text {root }}$. These data indicate that during the breeding process, root growth rate has generally improved under HN, but not under LN.

\subsubsection{Leaf area per plant}

Leaf area (LA) per plant at the seedling stage decreased with increasing year of hybrid release. This trend was the same in both $\mathrm{N}$ treatments $(r=-0.63$ for $\mathrm{LN}, P<0.10$; and $r=-0.65$ for $\mathrm{HN}, P<0.05$ ) (Figure 5), except for hybrid Denghai 661 in which LA increased with increasing year of release. The trend in LA was consistent with that in shoot dry weight (Figure 2). In general, it appears that modern maize hybrids are smaller than older hybrids.

\subsubsection{Root morphology}

Root morphology significantly changed with increasing year of hybrid release (Figure 6). As shown in Table 2, there was a strong interaction effect of N×genotype on root morphological traits. Total root length (TRL) was significantly positively related to increasing year of hybrid release under HN but not under LN (Figure 6A). The same trend was also observed for total lateral root length (LRL) and

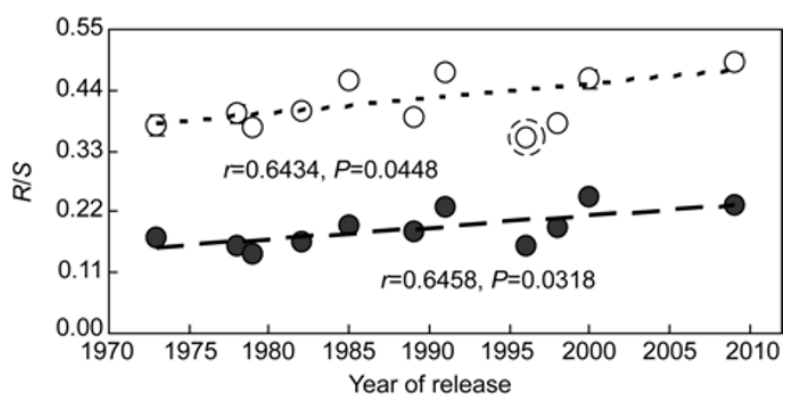

Figure 3 Ratio of root to shoot biomass $(R / S)$ of maize seedlings plotted against year of hybrid release. Data represent the average of four replicates. Open circles denote low $\mathrm{N}$ treatment; solid circles denote high $\mathrm{N}$ treatment. Dashed line and dotted line are linear regressions for $\mathrm{HN}$ and LN, respectively. Data point omitted from the regression analysis is circled.
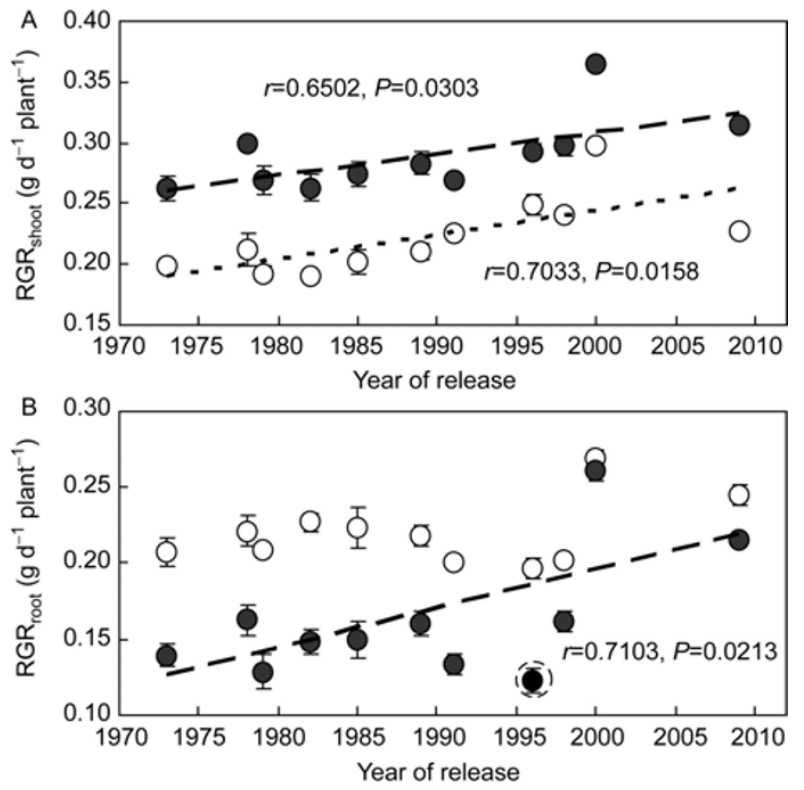

Figure 4 Relative growth rate for shoot dry weight ( $\mathrm{RGR}_{\text {shoot, }}$ above) and root dry weight $\left(\mathrm{RGR}_{\text {root}}\right.$, below) of maize seedlings plotted against year of hybrid release. Data represent the average of four replicates. Open circles denote low $\mathrm{N}$ treatment, solid circles denote high $\mathrm{N}$ treatment. Dashed line and dotted line are linear regressions for $\mathrm{HN}$ and $\mathrm{LN}$, respectively. Data point omitted from the regression analysis is circled.

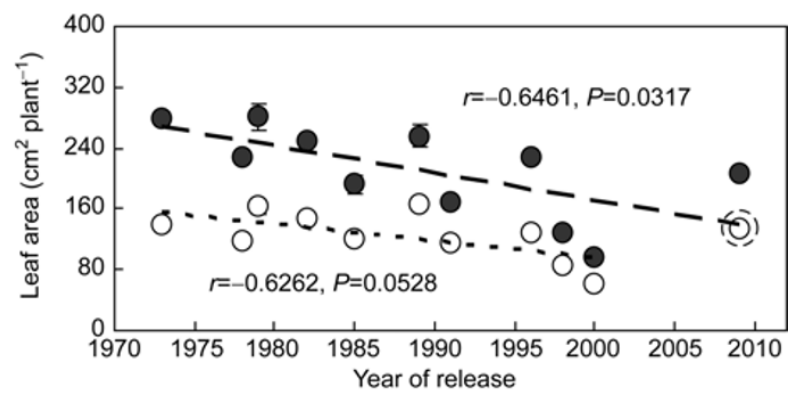

Figure 5 Leaf area per plant (LA) of maize seedlings plotted against year of hybrid release. Data represent the average of four replicates. Open circles denote low $\mathrm{N}$ treatment, full circles denote high $\mathrm{N}$ treatment. Dashed line and dotted line are linear regressions for HN and LN, respectively. Data point omitted from the regression analysis is circled.

total axial root length (ARL) (Figure 6B and C). These results suggest that root morphology has generally improved under optimal $\mathrm{N}$ input conditions, but has not changed under low $\mathrm{N}$ conditions. In fact, under low $\mathrm{N}$ conditions, the response of ARL in hybrids released after the 1990s was less than that in hybrids released prior to this (Figure 6C). With the exception of hybrid ZD2, seminal root number $(\mathrm{SRN})$ and total axial root number (ARN) per plant increased with increasing year of hybrid release (Figure 6D and $\mathrm{E})$. Once again, the increase of ARN was greater in $\mathrm{HN}$ than in LN conditions (Figure 6E).

\section{Discussion}

A better understanding of the root system is required to op- 

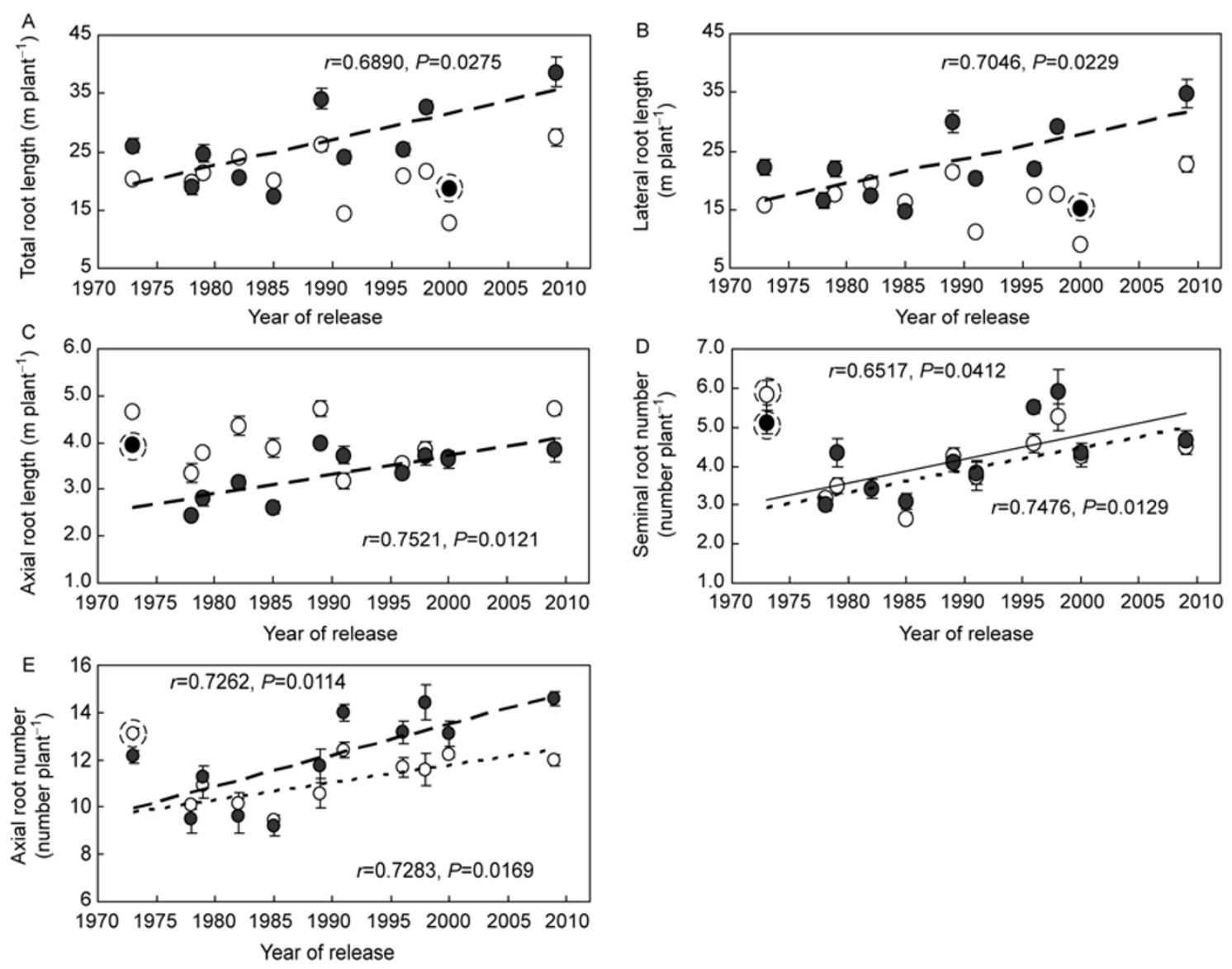

Figure 6 Total root length (A), total lateral root length (B), axial root length (C), number of seminal roots (D) and total number of axial roots (E) of maize seedlings plotted against year of hybrid release. Data represent the average of four replicates. Open circles denote low $\mathrm{N}$ treatment, full circles denote high $\mathrm{N}$ treatment. Dashed line and dotted line are linear regressions for HN and LN, respectively. Data points omitted from regression analyses are circled.

timize its function and to overcome the potential restrictions of soil factors (e.g., drought, waterlogging, nutrient heterogeneity, mechanical impedance, and/or pathogens) on the canopy, and to enhance yield [35]. Short-term HN treatment decreased RDW and $R / S$, compared with their respective values in LN (Figure 1), suggesting that less of the total photosynthetic carbon-assimilate was allocated to the roots [29]. However, carbon-assimilates seemed to be used more efficiently in the roots under $\mathrm{HN}$, because of the greater total root length (TRL) and total lateral root length (LRL) (Figure 1). Using different maize inbred lines, Wang et al. [12] also observed increases in TRL and LRL under high $(0.4$ to 4 mmol L $\left.{ }^{-1}\right)$ nitrate supply, compared with low $\left(0.04 \mathrm{mmol} \mathrm{L}^{-1}\right)$ nitrate supply. Nevertheless, they did not find a correlation between TRL and $\mathrm{N}$ accumulation at high $\mathrm{N}$ supply, suggesting that a large root system may not be required for efficient $\mathrm{N}$ uptake in those conditions. In the present study, the number of seminal roots (SRN) was barely affected by different $\mathrm{N}$ levels (Table 2, Figure 1). However, the total axial root length (ARL) per plant was decreased under HN (Figure 1), indicating that root elongation may be restricted, and that root systems tended to be shallower at high $\mathrm{N}$ supply. This finding is consistent with the results of Tian et al. $[36,37]$ who found that plants grown under high $\mathrm{N}$ may decrease root elongation via increased cytokinin levels and decreased auxin levels. Taken together, these results suggest that maize plants may adapt to low $\mathrm{N}$ environments by allocating more carbon-assimilates to the roots and enhancing axial root elongation so that they can capture the downwardmoving nitrates in the soil [38-40].

The significant genotypic effect on shoot and root growth parameters suggests that these traits have changed markedly during the breeding processes in recent decades (Table 2). However, there is little information on the changes in root traits that have occurred during maize breeding processes. Campos et al. [41] observed differences in water extraction between old and modern maize hybrids. During a period of water limitation, the old hybrid extracted more water from shallow soil horizons, whereas the new hybrid appeared to be more effective at extracting water at greater depths. This observation indicated that new hybrids may have greater rooting depth than old hybrids. The modeling work by 
Hammer [25] suggested that changes in the architecture of the root system and water capture directly affected biomass accumulation and historical yield trends in the USA. Here, we found that values for SDW (Figure 2) and LA (Figure 5) were lower in newly developed hybrids. This may be essential for the establishment of a high density population because smaller leaves help to reduce plant-to-plant competition for light resources. In fact, high-density tolerance has been a major breeding target for maize breeding in recent years in China [42], even though there are still some cultivars with a large shoot biomass (e.g., Denghai 661 in this study). To obtain high yields (approx. 15 ton per hectare), the recommended planting density for modern hybrids (e.g., ZD958 and XY335) is up to 70000 plants per hectare [42]. Interestingly, the smaller shoot dry weight in newly released cultivars had little effect on root dry weight (Figure 2), and as a result, the $R / S$ ratio increased (Figure 3 ). Also, the newly developed cultivars had higher TRL, LRL, and ARL under HN input (Figure 6). This improvement in root traits and the root-to-shoot relationship may contribute greatly to high yields and stress tolerance in new hybrids [43].

In this study, we found strong interaction effects of N×genotype on root traits. This suggests that the breeding process has significantly affected the root response to $\mathrm{N}$ nutrition (Table 2). Although TRL, LRL, and ARL were higher in newly developed hybrids under HN input, they were similar to those of older hybrids under LN conditions (Figure 6), suggesting that the high $\mathrm{N}$ conditions used in breeding programs may not improve root morphology. In fact, RDW was significantly lower in newly released hybrids under LN conditions (Figure 2), indicating that the adaptive response of RDW to LN stress decreased with increasing year of hybrid release (Figure 2). Interestingly, the response of axial root length (ARL) to low $\mathrm{N}$ stress was only observed in the hybrids released prior to the 1990s, but not in hybrids released afterwards (Figure 6C). Since axial root elongation is essential for nitrate and water uptake in deep soil, these results may indicate that the adaptive response of root growth to low $\mathrm{N}$ has been negatively affected during the past 20 years of selective breeding.

From the 1970 s to 2009 , there has been a strong tendency for seminal root number and total axial root number to increase with the year of hybrid release under both low and high $\mathrm{N}$ inputs (Figure 6D and $\mathrm{E}$ ). This result is consistent with those reported by Sun et al. [44], who found a marginal yet significant increase in nodal root number among hybrids released during the 1990 s compared with those released during the 1970s. The only exception was XY335, the only hybrid developed by the Pioneer Company. It had fewer axial roots (Figure 6E) and lower TRL and LRL (Figure 6A and B) compared with other hybrids released around the same time. XY335 performs very well at high planting densities [45], but is vulnerable to root-lodging $[46,47]$. The results in this study provide a reasonable explanation for this phenomenon, i.e., the small root system of
XY335 reduces plant-to-plant competition for nutrient and water resources, but is detrimental for root-lodging resistance. On the other hand, the oldest hybrid (ZD2) had more axial roots, including seminal roots, and longer axial roots compared with other hybrids released in the same period (Figure 6C, D and E). This cultivar is resistant to many stresses and is still planted in large areas of Gansu province, northwestern China, where drought is a serious problem [48].

Root vigor is interpreted as the ability to develop a root system quickly. This trait is linked to the capability of plants to capture $\mathrm{NO}_{3}^{-}$in soils with a high leaching potential [18]. Vigorous seedling development affects the amount of biomass at harvest in maize [49] and rice [50]. Relative growth rate (RGR) is an effective indicator of seedling vigor. This trait is heritable and is less influenced by environmental factors [51]. In this study, modern hybrids had higher $\mathrm{RGR}_{\text {shoot }}$ regardless of $\mathrm{N}$ treatments (Figure 4), suggesting that the shoot growth vigor has been increased by modern breeding. In the root, however, the genetic gain in seedling $\mathrm{RGR}_{\text {root }}$ was only seen under sufficient $\mathrm{N}$ supply, but not under LN (Figure 4). In fact, root dry weight under LN decreased with increasing year of hybrid release (Figure $2)$. Thus, root growth traits have been selected unconsciously to adapt and acclimate to the increasing $\mathrm{N}$ supply in the environment during conventional breeding, possibly because of the high level of $\mathrm{N}$ fertilizer in the breeding fields [52]. Under this high $\mathrm{N}$ environment, the early vigorous root growth may enhance early $\mathrm{N}$ uptake and help to reduce nitrate leaching. This differs from the situation in wheat, in which the root system of modern dwarf varieties is smaller than that of older taller varieties [19], and may be too small for optimum uptake of nutrients and further yield gains [20]. However, similar situations may occur in some modern maize hybrids, e.g., ZD958 in the present study, which had a lower $\mathrm{RGR}_{\text {root }}$ and a low $R / S$ ratio compared with those of hybrids released in the same decade (Figures 3 and 4).

\section{Conclusion}

Root growth and its response to $\mathrm{N}$ availability in Chinese maize hybrids have changed greatly between 1973 and 2009, as a result of high-yield breeding processes. While shoot growth vigor has improved at sufficient and limited $\mathrm{N}$ supply, the root growth rate, total root length, total lateral root length, total axial root length, seminal root number and axial root number have only improved under $\mathrm{N}$-sufficient conditions. Furthermore, an adaptive response of axial root length to low $\mathrm{N}$ stress was only observed in hybrids released before the 1990s, not in those released afterwards. Therefore, root growth traits have been selected unconsciously to adapt and acclimate to the increasing $\mathrm{N}$ supply in the environment over the past few decades. To increase $\mathrm{N}$ acquisi- 
tion efficiency under limited $\mathrm{N}$ supply, root growth rate and root morphology should be taken into consideration in maize breeding programs in the future.

This work was supported by the National Basic Research Program of China (Grant No. 2009CB11860), the National Natural Science Foundation of China (Grant Nos. 31071852 and 30821003) and the Special Fund for Agriculture Profession (Grant No. 201103003).

1 Tollenaar M. Genetic improvement in grain yield of commercial maize hybrid grown in Ontario from 1959 to 1988. Crop Sci, 1989, 29: $1365-1371$

2 Tollenaar M, Lee E A. Dissection of physiological processes underlying grain yield in maize by examining genetic improvement and heterosis. Maydica, 2006, 51: 399-408

3 Russell W A. Genetic improvement of maize yields. Adv Agron, 1991, 46: 245-298

4 Duvick D N. Genetic contributions to advances in yield of U.S. maize. Maydica, 1992, 37: 69-79

5 Qiao C G, Wang Y J, Guo H A, et al. A review of advances in maize production in Jilin Province during 1974-1993. Field Crops Res, 1996, 47: 65-75

6 Khush G S. Green revolution: preparing for the 21st century. Genome, 1999, 42: 646-655

7 Duvick D N, Cassman K G. Post-green revolution trends in yield potential of temperate maize in the north-central United States. Crop Sci, 1999, 39: 1622-1630

8 Xie Z J, Li M S, Xu J S, et al. Contributions of genetic improvement to yields of maize hybrids during different eras in north China. Sci Agri Sin, 2009, 42: 781-789

9 Raun W R, Johnson G V. Improving nitrogen use efficiency for cereal production. Agron J, 1999, 91: 357-363

10 Mackay A D, Barber S A. Effect of nitrogen on root growth of two corn genotypes in the field. Agron J, 1986, 77: 699-703

11 Pan W L, Jackson W A, Moll R H. Nitrate uptake and partitioning by corn (Zea mays L.) root systems and associated morphological differences among genotypes and stages of root development. J Exp Bot, 1985, 36: 1341-1351

12 Wang Y, Mi G H, Chen F J, et al. Response of root morphology to nitrate supply and its contribution to nitrogen accumulation in maize. J Plant Nutri, 2004, 27: 2189-2202

13 Hochholdinger F, Tuberosa R. Genetic and genomic dissection of maize root development and architecture. Curr Opin Plant Biol, 2009, 12: $172-177$

14 Liu J C, Li J S, Chen F, et al. Mapping QTLs for root traits under different nitrate levels at the seedling stage in maize (Zea mays L.). Plant Soil, 2008, 305: 253-265

15 Coque M, Martin A, Veyrieras J B, et al. Genetic variation for $\mathrm{N}$-remobilization and postsilking $\mathrm{N}$-uptake in a set of maize recombinant inbred lines.3. QTL detection and coincidences. Theor Appl Genet, 2008, 117: 729-747

16 Liu J C, Cai H G, Chu Q, et al. Genetic analysis of vertical root pulling resistance (VRPR) in maize using two genetic populations. Mol Breeding, 2010, DOI 10.1007/s11032-010-9496-z

17 Herder G D, Gert V I, Tom B, et al. The roots of a new green revolution. Trends Plant Sci, 2010, 15: 600-607

18 Garnett T, Vanessa C, Brent N K. Root based approaches to improving nitrogen use efficiency in plants. Plant Cell Environ, 2009, 32: 1272-1283

19 Siddique K H M, Belford R K, Tennant D. Root: shoot ratios of old and modern, tall and semi-dwarf wheats in a mediterranean environment. Plant soil, 1990, 121: 89-98

20 Waines G J, Bahman E. Domestication and crop physiology: roots of green-revolution wheat. Ann Bot, 2007, 100: 991-998
21 Wilson H K. Plant characters as indices in relation to the ability of corn strains to withstand lodging. J Am Soc Agron, 1930, 22: 453-458

22 Jenison J R, Shank D B, Penny L H. Root characteristics of 44 maize inbreds evaluated in four environments. Crop Sci, 1981, 21: 233-237

23 Landi P, Albrecht B, Giuliani M M, et al. Seedling characteristics in hydroponic culture and field performance of maize genotypes with different resistance to root lodging. Maydica, 1998, 43: 111-116

24 Clarke J M, McCaig T N. Breeding for efficient root systems. In: Hayward M D, Osemark M O, Ramagosa I, Eds. Plant Breeding: Principles and Prospects. London: Chapmann \& Hall, 1993. 485-499

25 Hammer G L. Can changes in canopy and/or root system architecture explain historical maize yield trends in the U.S. Corn Belt? Crop Sci, 2009, 49: 299-312

26 Hirel B, Le G J, Ney B, et al. The challenge of improving nitrogen use efficiency in crop plants: towards a more central role for genetic variability and quantitative genetics within integrated approaches. J Exp Bot, 2007, 58: 2369-2387

27 Liu J C, Li J S, Mi G H, et al. QTL Mapping of seedling growth traits and grain yield under two nitrogen conditions in maize. Sci Agri Sin, 2009, 42: 3413-3420

28 Cai H G. Quantitative trait locus (QTL) analysis of root and nitrogen and phosphorus efficiency related traits in maize. Dissertation for Doctoral Degree. Beijing: China Agricultural University, 2009

29 Feil B. Breeding progress in small grain cereals-a comparison of old and modern cultivars. Plant Breeding, 1992, 108: 1-11

30 Tong $\mathrm{P}$ Y. The course and the achievement of corn variety improving in the $20^{\text {th }}$ century in China. China Histor Mater Sci Technol, 2001, 22: $113-127$

31 Zhang J L. Maize variety evolution since 1982 in China. J Henan Agri Sci, 2008, 6: 36-39

32 Wolt J P, Song C M. Dymamic-stiffness matrix of unbounded soil by finite-element multi-cell cloning. Earthquake Eng Struc Dyn, 1994, 23: $233-250$

33 Sanderson J B, Daynard T B, Tollenaar M. A mathematical model of the shape of corn leaves. Can J Plant Sci, 1981, 61: 1009-1011

34 Botella M, Martinez V, Nieves M, et al. Effect of salinity on the growth and nitrogen uptake by wheat seedlings. J Plant Nutri, 1997, 20: 793-804

35 Bingham I J. Soil-root-canopy interactions. Ann Appl Biol, 2001, 138: 243-251

36 Tian Q Y, Chen F J, Zhang F S, et al. Possible involvement of cytokinin in nitrate-mediated root growth in maize. Plant Soil, 2005, 277: $185-196$

37 Tian Q Y, Chen F J, Liu J X, et al. Inhibition of maize root growth by high nitrate supply is correlated to reduced IAA levels in roots. J Plant Physiol, 2008, 165: 942-951

38 Wiesler F, Horst W J. Differences among maize cultivars in the utilization of soil nitrate and the related losses of nitrate through leaching. Plant Soil, 1993, 151: 193-203

39 Wiesler F, Horst W J. Root growth and nitrate utilization of maize cultivars under field conditions. Plant Soil, 1994, 163: 267-277

40 Mi G H, Chen F J, Wu Q P, et al. Ideotype root architecture for efficient nitrogen acquisition by maize in intensive cropping systems. Sci China Ser C, 2010, 53: 1369-1373

41 Campos H M, Cooper J E, Habben G O, et al. Improving drought tolerance in maize: A view from industry. Field Crops Res, 2004, 90 : 19-34

42 Li S K, Wang C. Evolution and development of maize production techniques in China. Sci Agri Sin, 2009, 42: 1941-1951

43 Duvick D N. The contribution of breeding to yield advances in maize (Zea mays L.). Adv Agron, 2005, 86: 83-145

44 Sun Q Y, Hu C H, Dong S T, et al. Evolution of root characters during all growth stage of maize cultivars in different eras in China. Acta Agron Sin, 2003, 29: 641-645

45 Chen C Y, Hou H P, Li Q, et al. Effects of panting density on photo- 
synthetic characteristics and changes of carbon and nitrogen in leaf of different corn hybrids. Acta Agron Sin, 2010, 36: 871-878

46 He D Y, Zhou L D, Liu J W, et al. A preliminary study on the role of US maize germplasm resources in maize breeding in China. Bull Agri Sci Techno, 2009, 4: 5-6

47 Yang J S, Wang Y J, Zhang J W, et al. Dry matter production and photosynthesis characteristics of three hybrids of maize (Zea mays L.) with super-high-yielding potential. Acta Agron Sin, 2011, 37: 355-361

48 Zhang W X, Zhao Z, Bai G X, et al. Response on water stress and low nitrogen in different maize hybrid varieties and evaluation for their adversity-resistance. Sci Agri Sin, 2007, 7: 1361-1370
49 Peter R T, Eschholz W, Stamp P, et al. Swiss maize landraces-early vigour adaptation to cool conditions. Acta Agronomica Hungarica, 2006, 54: 329-336

50 Reinke R F, Richards R A, Angus J F, et al. Early vigor: an important foundation for rapid biomass accumulation. International Rice Research Institute Los Baños, Laguna, the Philippines, 2002. $429-438$

51 Fakorede M A B, Ojo D K. Variability for Seedling Vigour in Maize. Exp Agric, 1981, 17: 195-201

52 Cirilo A G, Dardanelli J, Balzarini M, et al. Morpho-physiological traits associated with maize crop adaptations to environments differing in nitrogen availability. Field Crops Res, 2009, 113: 116-124

Open Access This article is distributed under the terms of the Creative Commons Attribution License which permits any use, distribution, and reproduction in any medium, provided the original author(s) and source are credited. 